\title{
Pengelolaan Surat Menyurat Majelis Kehormatan Etik Kedokteran
}

\author{
Putri Dianita Ika Meilia ${ }^{\mathrm{I}, 2}$, Anna Rozaliyani ${ }^{\mathrm{I}, 3}$, Nurfanida Librianty ${ }^{\mathrm{I}, 4}$ \\ ${ }^{\mathrm{I}}$ Majelis Kehormatan Etik Kedokteran Pengurus Besar Ikatan Dokter Indonesia \\ ${ }^{2}$ Instalasi Kedokteran Forensik dan Pemulasaraan Jenazah, Rumah Sakit Umum Pusat Persahabatan, Jakarta \\ ${ }^{3}$ Departemen Parasitologi, Fakultas Kedokteran Universitas Indonesia \\ ${ }^{4}$ Fakultas Kedokteran Universitas Pembangunan Nasional Veteran Jakarta
}

\author{
Kata Kunci \\ MKEK, surat, tata laksana \\ Korespondensi \\ contact@ilmiah.id \\ Publikasi \\ (C) 20I8 JEKI/ilmiah.id \\ DOI \\ I0.26880/jeki.v2i3.26 \\ Tanggal masuk: I Agustus 2018 \\ Tanggal ditelaah: 15 Oktober 2018 \\ Tanggal diterima: 21 Oktober 2018 \\ Tanggal publikasi: 24 Oktober 2018
}

\begin{abstract}
Abstrak Sebagai badan otonom Ikatan Dokter Indonesia (IDI) yang bertanggung jawab dalam penerapan etika kedokteran, ketertiban administratif adalah sangat penting bagi Majelis Kehormatan Etik Kedokteran (MKEK), terutama karena banyak berurusan dengan masalah sensitif dan rahasia yang menyangkut hajat hidup teman sejawat dan kewibawaan MKEK maupun IDI. Oleh karena itu, MKEK sudah sepatutnya memiliki aturan tentang pengelolaan surat menyurat untuk melancarkan komunikasi dan koordinasi dengan berbagai pihak dan agar tertib secara administratif. Setiap MKEK wilayah/cabang hendaknya memiliki aturan internal tentang pengelolaan surat menyurat, yang dapat dibuat dengan merujuk ke Standar Prosedur Operasional yang telah dibuat oleh MKEK Pusat.
\end{abstract}

Abstract As an autonomous body of Indonesian Doctors Association (IDI) which is responsible for implementation of medical ethics, administrative order is very important for the Medical Ethics Council of Honor (MKEK), especially because it deals with sensitive and confidential issues which concern the lives of colleagues as well as dignity of MKEK and IDI. Therefore, MKEK should have rules regarding its management of correspondence to facilitate communication and coordination with various parties and to be administratively orderly. Each regional/branch MKEK should have internal rules regarding its own management of correspondence, which can refer to the Standard Operating Procedure made by the Central MKEK.

\section{PENDAHULUAN}

Majelis Kehormatan Etik Kedokteran (MKEK) ialah badan otonom Ikatan Dokter Indonesia (IDI) yang bertanggung jawab mengkoordinasi kegiatan internal organisasi dalam pengembangan kebijakan, pembinaan pelaksanaan dan pengawasan penerapan etika kedokteran., ${ }^{1,2}$ Dalam melaksanakan tugasnya, MKEK melakukan beragam kegiatan administratif. Salah satu kegiatan administratif yang paling mendasar adalah kegiatan surat menyurat, baik yang bersifat internal maupun eksternal dengan berbagai pihak. Contoh penggunaan surat di lingkungan MKEK, antara lain, mulai dari undangan rapat internal yang bersifat sederhana, surat pemberitahuan pemanggilan dokter teradu dalam rangka pembahasan kasus dugaan pelanggaran etik, sampai surat pengantar keputusan kemahkamahan.

Adanya ketertiban secara administratif sangat penting di lingkungan MKEK. Hal ini bukan saja disebabkan karena seringkali sifat masalah yang dibahas bersifat sensitif dan rahasia, namun tidak jarang juga menyangkut hajat hidup teman sejawat dan kewibawaan lembaga MKEK dan IDI di mata sejawat, sesama organisasi profesi, dan masyarakat itu sendiri. Oleh karena itu, adanya aturan yang jelas dan baku tentang pengelolaan surat menyurat penting untuk dibuat. Dalam artikel ini akan dibahas perihal pengelolaan kegiatan surat menyurat di lingkungan MKEK. 


\section{HASIL DAN PEMBAHASAN}

Selama kepengurusan MKEK periode 2015 - 2018, di tingkat MKEK Pusat telah disusun 2 Standar Prosedur Operasional (SPO) terkait surat menyurat, yaitu $\mathrm{SPO}$ surat masuk dan SPO surat keluar. Kedua SPO tersebut mencakup surat menyurat dalam bentuk surat fisik (hardcopy). Surat menyurat dalam bentuk surat elektronik (email), khususnya yang terkait dengan kasus aduan dugaan pelanggaran etika, diatur secara tersendiri.

Prosedur pengelolaan yang telah ditetapkan dalam SPO tersebut adalah sebagai berikut:

1) Prosedur surat keluar:

a) Pembuatan konsep surat:

i) Pembuatan konsep adalah kegiatan membuat rencana dan penyusunan penulisan surat-surat keluar;

ii) Pimpinan membuat dan mengetik sendiri untuk surat-surat yang sifatnya rahasia;

iii) Konsep surat yang tidak bersifat rahasia dapat dibuat oleh pimpinan lalu diserahkan kepada juru ketik/ sekretaris untuk diketik, atau dapat didiktekan langsung oleh pimpinan kepada sekretaris; atau dibuat oleh orang yang ditunjuk secara khusus (konseptor);

iv) Apabila konsep surat dianggap sudah selesai/sudah dilengkapi, diserahkan kembali kepada pimpinan untuk diperiksa.

b) Persetujuan konsep surat: i) Konsep surat yang telah dibuat oleh konseptor dimintakan persetujuan pada pimpinan;

ii) Apabila terdapat koreksi dari pimpinan, maka konseptor/sekretaris memperbaiki konsep surat;

iii) Setelah konsep surat tersebut dibetulkan oleh pimpinan, maka pimpinan memberi paraf persetujuan (acc) pada konsep tersebut.

c) Pencatatan surat:

i) Surat keluar harus diagendakan/ dicatat ke dalam buku agenda surat keluar;

ii) Surat keluar diberi nomor urut agenda sebagai nomor surat yang akan dikirim, dengan sistem penomoran sebagai berikut:

(1) Kode pertama: nomor urut surat keluar (misalnya "1234"),

(2) Kode kedua: "PB",

(3) Kode ketiga: "MKEK",

(4) Kode keempat: bulan pembuatan surat dalam angka dua digit (misalnya, bulan April ditulis sebagai "04"),

(5) Kode kelima: tahun pembuatan surat dalam angka empat digit (misalnya, "2015”).

d) Pengetikan konsep surat:

i) Setelah konsep surat mendapat persetujuan dari pimpinan dan telah diberi nomor, maka konsep surat tersebut diserahkan kepada juru ketik/ sekretaris untuk diketik;

ii) Hasil pengetikan konsep surat tersebut

Istilah-istilah terkait yang terdapat di dalam SPO tersebut adalah:

\begin{tabular}{ll}
\hline Istilah & Definisi \\
\hline Pengelolaan & $\begin{array}{l}\text { Proses yang membantu perumusan kebijakan dan tujuan organisasi atau proses } \\
\text { yang memberikan pengawasan pada suatu hal yang terlibat dalam pelaksanaan } \\
\text { kebijakan dan pencapaian tujuan. }\end{array}$ \\
& $\begin{array}{l}\text { Setiap tulisan yang berisi pernyataan dari penulisnya dan bertujuan } \\
\text { Surat }\end{array}$ \\
menyampaikan informasi kepada pihak lain; alat komunikasi tertulis. \\
Surat keluar & $\begin{array}{l}\text { Semua jenis surat yang dikirimkan ke instansi lain atau ke perorangan, baik yang } \\
\text { dikirimkan melalui pos, kurir (pengantar), atau diserahkan secara langsung. }\end{array}$ \\
& $\begin{array}{l}\text { Semua jenis surat yang diterima dari instansi lain atau dari perorangan, baik } \\
\text { yang diterima melalui pos, kurir (pengantar), atau diserahkan secara langsung. }\end{array}$
\end{tabular}


(bentuk surat jadi) diberikan kepada pimpinan untuk diperiksa kembali.

e) Penandatanganan surat dan pemberian cap stempel:

i) Apabila tidak ada koreksi dari pimpinan, bentuk surat jadi tersebut disampaikan kepada pimpinan, atau pejabat yang berwenang, unuk ditandatangani;

ii) Surat jadi dibubuhi cap stempel MKEKPB IDI.

f) Pengiriman surat, dapat dilakukan dengan dua cara, yaitu:

i) Dikirim langsung/diantar oleh kurir dengan menggunakan buku ekspedisi eksternal, atau

ii) Dikirim melalui pos.

2) Prosedur surat masuk:

a) Penerimaan:

i) Mengumpulkan dan menghitung jumlah surat yang masuk;

ii) Meneliti ketepatan alamat yang dituju oleh si pengirim;

iii) Menandatangani bukti pengiriman sebagai tanda bahwa surat telah diterima.

b) Penyortiran:

i) Memisahkan surat-surat berdasarkan pihak yang dituju atau jenis surat;

ii) Memberi tanda pada surat berdasarkan penggolongan dengan kode sebagai berikut:

(1) Kode "SM_a": Surat pengaduan

(2) Kode "SM_b": Surat permintaan fatwa/opini etik

(3) Kode "SM_c": Pelaporan/hasil sidang MKEK wilayah

(4) Kode "SM_d": Laporan hasil pembinaan

(5) Kode "SM_e": Surat undangan rapat/acara

(6) Kode "SM_f": Surat pemberitahuan/sosialisasi

(7) Kode "SM_g": Surat terkait program.

c) Pembukaan surat:

i) Setelah disortir, surat-surat dibuka satu persatu sambil diteliti tentang kelengkapan-kelengkapan yang ada; ii) Setelah surat dibuka isinya dikeluarkan dan tetap disertakan amplopnya (dengan distaples);

iii) Langkah ini dikecualikan untuk suratsurat yang bertandakan "RAHASIA" atau "RHS", atau surat-surat yang bersifat pribadi (ditujukan pada perorangan yang disebutkan namanya).

d) Pencatatan:

i) Membaca dan meneliti perihal/ maksud surat;

ii) Memeriksa lampiran-lampiran surat;

iii) Membubuhkan cap yang merupakan stempel agenda pada ruang yang kosong di bagian atas/bawah halaman pertama surat;

iv) Mengagendakan surat masuk, yaitu mencatat surat tersebut dalam buku penerimaan untuk surat masuk dan melakukan penomoran surat sesuai urutan masuknya surat.

e) Pengarahan dan penerusan:

i) Langkah ini berlaku untuk surat-surat yang perlu diproses lebih lanjut. Suratsurat tersebut harus diarahkan dan diteruskan kepada pejabat yang berhak mengolahnya;

ii) Surat masuk harus disertai lembar disposisi;

iii) Surat masuk yang telah dilengkapi dengan lembar disposisi diteruskan kepada pimpinan/kepala bagian untuk memperoleh tanggapan atas isi surat dengan menegaskan pada lembaran disposisi tersebut berupa instruksi atau informasi;

iv) Surat yang telah memperoleh disposisi disampaikan kembali kepada sekretariat/tata usaha;

v) Selanjutnya surat tersebut diteruskan kepada unit pengolah untuk diproses sesuai dengan disposisi.

f) Penyampaian surat:

i) Surat yang berdisposisi dicatat dalam buku ekspedisi internal;

ii) Petugas menyampaikan surat tersebut melalui buku ekspedisi kepada pejabat yang bersangkutan;

iii) Buku ekspedisi diparaf oleh pejabat 
yang menerima sebagai tanda surat telah diterima.

g) Penyimpanan berkas/arsip surat masuk: Surat-surat yang ditandai "Untuk Arsip" harus disimpan sesuai dengan SPO Pengarsipan.

Contoh buku agenda yang dipakai adalah sebagai berikut, mengikuti format yang digunakan di Arsip Nasional Republik Indonesia sesuai dengan Peraturan Kepala ANRI no. 33 tahun 2012: ${ }^{3}$

\section{Buku Agenda Surat Masuk}

\begin{tabular}{|c|c|c|c|c|c|c|c|c|c|c|}
\hline \multirow{2}{*}{$\begin{array}{l}\text { No. } \\
\text { Urut }\end{array}$} & \multirow{2}{*}{$\begin{array}{l}\text { Tgl. Teríma } \\
\text { Surat }\end{array}$} & \multirow{2}{*}{$\begin{array}{l}\text { Asal } \\
\text { Surat }\end{array}$} & \multirow[b]{2}{*}{$\begin{array}{l}\text { Tgl. } \\
\text { Surat }\end{array}$} & \multirow{2}{*}{$\begin{array}{l}\text { Nomor } \\
\text { Surat }\end{array}$} & \multirow{2}{*}{$\begin{array}{c}\text { Isi } \\
\text { Ringkas }\end{array}$} & \multirow{2}{*}{$\begin{array}{l}\text { Tujuan } \\
\text { Surat }\end{array}$} & \multirow[b]{2}{*}{$\begin{array}{l}\text { Unit } \\
\text { Pengolah }\end{array}$} & \multicolumn{2}{|c|}{ Penerimaan } & \multirow[b]{2}{*}{ Ket. } \\
\hline & & & & & & & & $\begin{array}{l}\text { Paraf \& } \\
\text { Nama }\end{array}$ & Tgl. & \\
\hline (1) & (2) & (3) & (4) & (5) & (6) & (7) & (8) & (9) & (10) & (111) \\
\hline & & & & & & & & & & \\
\hline & & & & & & & & & & \\
\hline & & & & & & & & & & \\
\hline
\end{tabular}

Keterangan :
(1) No.Urut
diisi nomor urut surat masuk di unit kearsipan
(2) Tgl, Terima Surat
diisi tanggal surat diterima di unit kearsipan
(3) Asal Surat
: disi nama atau instansi pengirim surat
diisi tanggal yang tertera pada surat
(4) Tanggal Surat
diisi nomor yang tertera pada surat
diisi isi ringkas dari surat
(6) Isi Ringkas
(7) Tujuan Surat
(8) Unit Pengolah
diisi alamat tujuan yang tertera pada surat
: diisi unit pengolah tujuan surat setelah
diarahkan sesuai dengan isi ringkas surat
(9) Paraf dan nama Penerima
diisi paraf dan nama penerima surat di unit
pengolah
(10) Tgl.
: diisi tanggal penerimaan surat di unit
pengolah
(11) Ket. (Keterangan)
diisi hal -hal yang tidak tercakup dalam kolom lain seperti surat berupa faks/email, tidak ada lampiran atau lampiran tidak lengkap.

\section{Buku Agenda Surat Keluar}

\begin{tabular}{|c|c|c|c|c|c|c|}
\hline No. Urut & $\begin{array}{c}\text { Tgl. } \\
\text { Terima } \\
\text { Surat }\end{array}$ & $\begin{array}{c}\text { Tgl. } \\
\text { Surat }\end{array}$ & Nomor Surat & Isi Ringkas & Tujuan Surat & Ket. \\
\hline$(1)$ & $(2)$ & $(3)$ & $(4)$ & $(5)$ & $(6)$ & $(7)$ \\
\hline & & & & & & \\
& & & & & & \\
& & & & & & \\
\hline
\end{tabular}

Keterangan:

(1) No. Urut: diisi nomor urut surat keluar yang siap untuk dikirim

(2) Tgl. Terima surat: diisi tanggal surat siap dikirim

(3) Tgl. Surat: diisi tanggal yang tertera pada surat

(4) Nomor surat: diisi nomor yang tertera pada surat

(5) Isi ringkas: diisi isi ringkas dari surat

(6) Tujuan surat: diisi alamat tujuan yang tertera pada surat

(7) Ket.: diisi dengan hal-hal yang tidak tercakup pada kolom lainnya.
Kegiatan surat menyurat berperan cukup penting dalam memperlancar kegiatan administrasi MKEK. Tercapainya tertib administratif yang terkait dengan surat masuk yang diterima dan surat keluar yang diterbitkan merupakan salah satu ukuran bagi keberhasilan suatu organisasi. Selain itu, pengelolaan surat yang baik juga menjamin kelancaran komunikasi dan koordinasi dengan berbagai pihak, seperti antara sesama pengurus MKEK dan antara organisasi MKEK dengan organisasi lainnya, baik dalam lingkup IDI maupun lembaga lainnya yang terkait.

Pembuatan dan pengelolaan surat yang baik juga sangat membantu dalam pelaksanaan kegiatan kemahkamahan, yaitu berupa pengelolaan surat masuk dan surat keluar terkait kasus dugaan pelanggaran etika. Khusus dalam hal ini, penerimaan surat aduan adanya dugaan pelanggaran etika, baik dari pasien/masyarakat maupun dari sejawat, harus dilaksanakan sesuai prosedur agar memberikan kesan yang profesional kepada pengadu. Sebagai keluaran, pembuatan konsep surat yang baik, dengan bahasa yang tegas namun tetap bersahabat, dapat mencerminkan semangat kesejawatan sehingga menimbulkan kesan yang tidak mengerikan bagi sejawat yang terdampak.

Satu hal yang tidak boleh dilupakan adalah masalah aspek kerahasiaan dari surat yang diterima maupun dikeluarkan oleh MKEK, khususnya yang terkait dengan kasus dugaan pelanggaran etika. Semua surat, lampiran, dan draft terkait harus disimpan dengan baik dan aman, baik dalam bentuk fisik (hardcopy) maupun elektronik (softcopy). Selain untuk menjamin kerahasiaan semua pihak yang terkait dengan aduan, terutama identitas dokter teradu dan pihak pengadu, pengelolaan surat yang baik diperlukan sebagai bukti telah diikutinya prosedur terkait apabila ada perselisihan atau masalah di kemudian hari.

\section{KESIMPULAN}

Sebagai badan otonom organisasi IDI, MKEK sudah sepatutnya memiliki aturan tentang pengelolaan surat menyurat untuk melancarkan komunikasi dan koordinasi 
dengan berbagai pihak dan agar tertib secara administratif. Setiap MKEK wilayah/cabang hendaknya memiliki aturan internal tentang pengelolaan surat menyurat, yang dapat dibuat dengan merujuk ke SPO yang telah dibuat oleh MKEK Pusat.

\section{KONFLIK KEPENTINGAN}

Tidak ada konflik kepentingan

\section{REFERENSI}

1. Muktamar Ikatan Dokter Indonesia XXIX. Anggaran dasar dan anggaran rumah tangga Ikatan Dokter Indonesia. 2015.

2. Purwadianto A, editor. Pedoman organisasi dan tata laksana kerja Majelis Kehormatan Etik Kedokteran. Jakarta: Majelis Kehormatan Etika Kedokteran Ikatan Dokter Indonesia; 2008.

3. Peraturan Kepala Arsip Nasional Republik Indonesia nomor 33 tahun 2012 tentang pedoman pengurusan surat di lingkungan Arsip Nasional Republik Indonesia. 2012. 

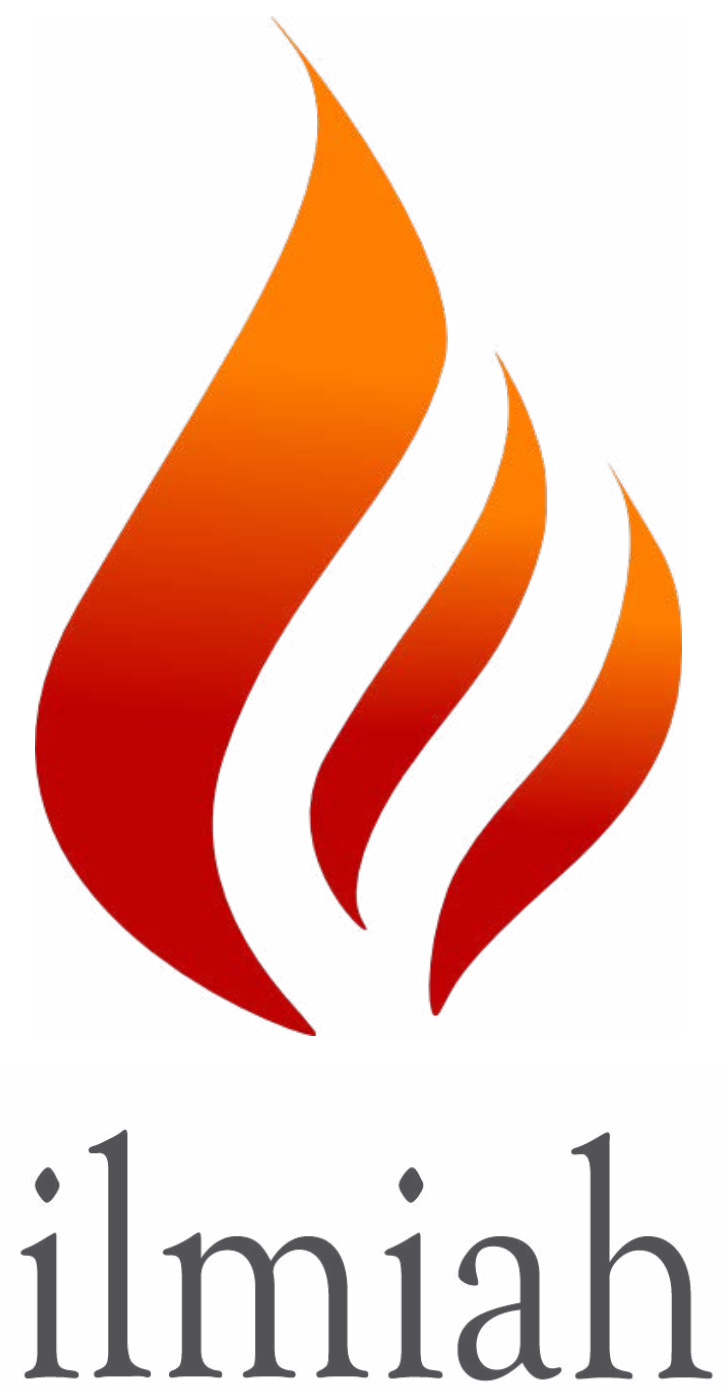

http://www.ilmiah.id your journal portal 